\title{
How Effective is "Lifetime Health Cover" in Raising Private Health Insurance Coverage in Australia? An Assessment Using Regression Discontinuity
}

\author{
Alfons Palangkaraya and Jongsay Yong \\ Melbourne Institute of Applied Economic and Social Research \\ and \\ Centre for Microeconometrics \\ The University of Melbourne
}

Melbourne Institute Working Paper No. 33/04

ISSN 1328-4991 (Print)

ISSN 1447-5863 (Online)

ISBN 0734031750

December 2004

Melbourne Institute of Applied Economic and Social Research The University of Melbourne

Victoria 3010 Australia

Telephone (03) 83442100

Fax (03) 83442111

Email melb-inst@unimelb.edu.au

WWW Address http://www.melbourneinstitute.com 


\begin{abstract}
The Australian government introduced three major private health insurance policy initiatives in recent years. These are, in chronological order, (i) the Private Health Insurance Incentives Scheme (PHIIS), which imposes a tax levy on high-income earners who do not have PHI, and provides a means-tested subsidy schedule for low-income earners who purchase PHI; (ii) a $30 \%$ premium rebate for all private health insurance policies to replace the means-tested component under PHIIS; and (iii) Lifetime Health Cover, which permits a limited form of age-related risk rating by insurance funds. Together, these policy changes have been effective in encouraging the uptake of PHI; the percentage of the population covered by PHI rose from 31\% in 1999 to $45 \%$ at the end of 2001 . The difficult issue, however, is in disentangling the effects of the three policy changes, given that they were introduced in quick succession. This paper attempts to evaluate the effect of Lifetime Health Cover using a regression discontinuity design, an approach that makes use of cross-section data that allows the effect of Lifetime Health Cover to be isolated via local regression. The results suggest that the importance of Lifetime Health Cover appears to be grossly over-rated in previous studies. Our estimates indicate that it accounts for roughly $30 \%$ to $44 \%$ of the combined effects of all the policy initiatives introduced in the late 1990s. While these figures suggest that its effect is clearly significant, it is nonetheless nowhere near the effect often associated with Lifetime Health Cover.
\end{abstract}

Keywords: Private Health Insurance, Lifetime Health Cover, Community Rating, Regression Discontinuity.

JEL Classifications: I11, I18 


\section{Introduction}

Private health insurance (PHI) has traditionally been an important component of the Australian health system. However, since the introduction of Medicare in 1984, the coverage of PHI has been on a steady decline until recent years. This downward trend has been reversed after the Australian government introduced three major policy changes to the private health insurance market over a three-year time period, from 1997 to 2000. Figure 1 shows the timing of the policy changes and the proportion of the population with PHI coverage.

\section{Figure 1: Percentage of the Australian population with PHI}

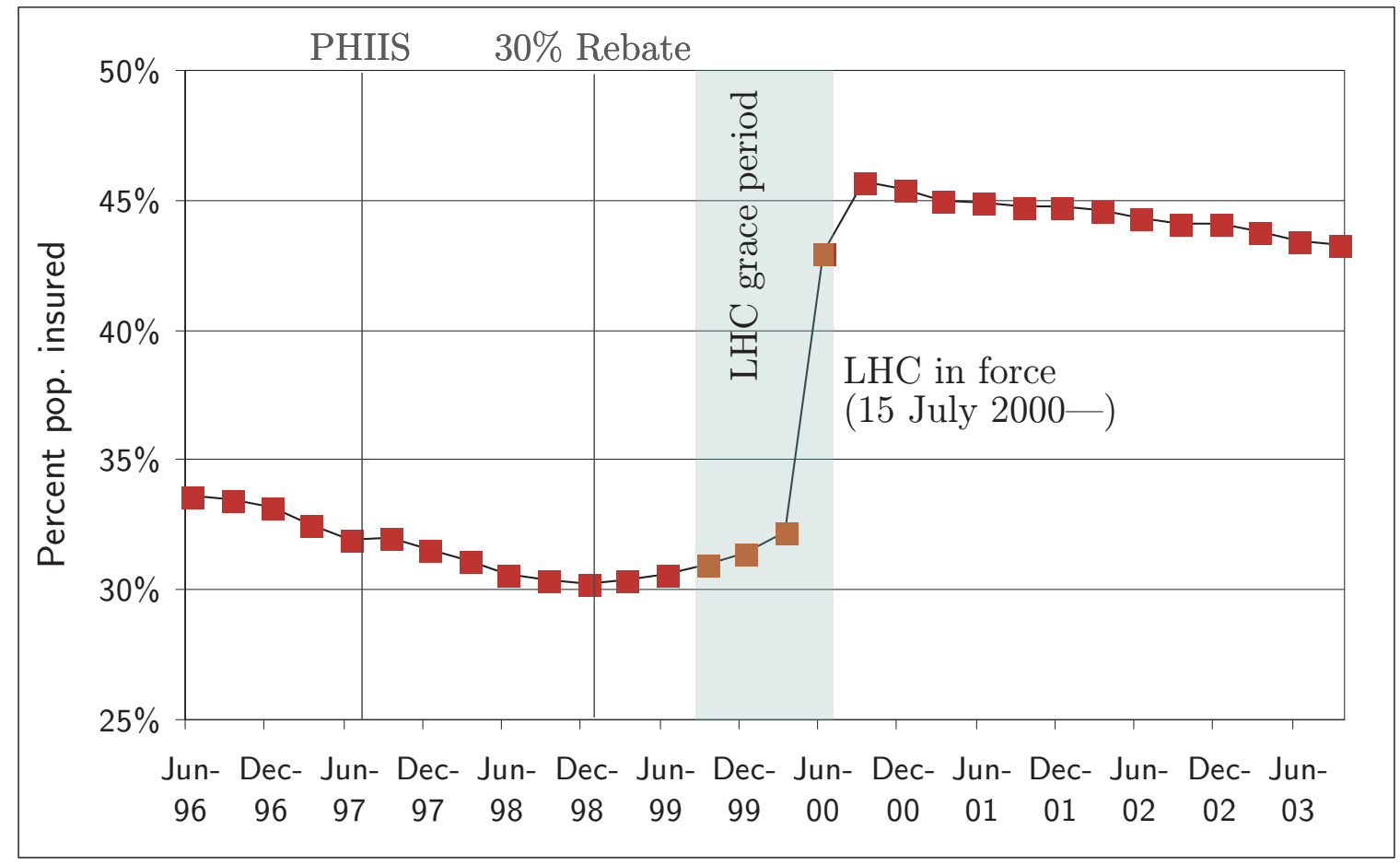

PHIIS $=$ Private Health Insurance Incentives Scheme

LHC $=$ Lifetime Health Cover Scheme

Source: PHIAC (www.phiac.gov.au)

The three major policy initiatives are, in chronological order, the Private Health Insurance Incentives Scheme (PHIIS), a 30 per cent insurance premium rebate, and the Lifetime Health Cover (LHC) scheme. The government introduced PHIIS in July 1997, 
under which high-income earners were "encouraged" to purchase PHI by the introduction of a tax levy. At the same time, a means-tested partial refund on health insurance premiums was made available to low-income households. The response to these policy changes was apathetic; the percentage of the population with PHI actually fell from 31.9 in June 1997 to 30.1 at the end of 1998. The PHIIS was amended in 1999, with the means-tested subsidy component replaced by a 30 per cent premium rebate regardless of income and applicable to both new and existing policies. The response to the rebate was slow but did lead to a small increase in the percentage of the population with private health insurance. The rebate was initially estimated to cost the government $\$ 1.09$ billion. However, with substantial increases in new members after the introduction of LHC in July 2000, the cost was $\$ 1.4$ b for the first year (1999-2000), and was in excess of $\$ 2 \mathrm{~b}$ in subsequent years.

The third major policy changes was introduced in July 2000, when a limited form of risk rating known as "Lifetime Health Cover," was built into PHI premiums. Prior to LHC, health insurance funds were required, under the community rating regulations, to charge a uniform premium for any given policy regardless of health risk. LHC allows a certain degree of risk rating by allowing health insurance funds to vary premiums according to the member's age at entry into the fund. Under LHC, anyone above 30 years of age when joining a health fund will be required to pay a higher premium, calculated at 2 per cent per year for every year of age above 30 years at the time of entry. ${ }^{1}$ This policy initiative was announced in September 1999, but took effect only in July 2000 to allow for a nine-month "grace period" for people with no PHI to purchase one and avoid paying the higher premiums.

These policy changes, taken together, have been effective in raising the coverage of PHI. The percentage of population covered by PHI rose from 31 per cent in 1999 to a high of 45 per cent at the end of 2001. However, the difficult issue is in disentangling the effects of the three policy changes, given that they were introduced in quick succession,

\footnotetext{
${ }^{1}$ Note that a ceiling of 70 per cent applies, and the premium is determined at entry and once determined, would not rise with the member's age. Also, people over the age of 65 years in July 2000 are exempt from LHC.
} 
and often one on top of the others. It is important to isolate the effect of each of the policy initiatives, as they involve different fiscal implications for the government. The 30 per cent premium rebate, for example, costs more than $\mathrm{A} \$ 2 \mathrm{~b}$ a year, while LHC is merely a legislative change and it involves minimal cost. Previous attempts to identify the effects, by Butler (2002), Hancock and Neal (2003), and Frech et al. (2003), rely almost exclusively on time series data. The consensus appears to be that PHIIS is the least effective policy change, the 30 per cent premium rebate has had some but limited effects, while LHC has been the most effective, and is responsible for most of the increase in PHI memberships. Partly because of the results from these studies, and partly due to the high fiscal cost of the 30 per cent premium rebate, there has been mounting political pressure to tinker with the rebate scheme.

One difficulty with using time series data on PHI coverage is the fact that LHC was introduced on top of the 30 per cent rebate and the tax levy introduced earlier on. Thus the increase in PHI coverage after the introduction of LHC cannot be attributed solely to LHC. This point is relevant because an individual's insurance decision is a binary one: one either purchases PHI or one does not. In the context of a standard discrete choice utility model, underlying this decision is an individual's perceived utility of buying PHI; when the utility crosses a certain threshold, one purchases PHI. Many factors may raise or lower the perceived utility of buying PHI. It is conceivable that one policy change, say the 30 per cent rebate, is not sufficient to push perceived utility over the threshold for most people, but with an additional policy, say LHC on top of the 30 per cent rebate, it may be sufficient for many individuals to cross the threshold. For this reason, it is incorrect to attribute most or all of the effects to the later policy changes.

This paper attempts to evaluate the effect of LHC using regression discontinuity (RD) design, which makes use of cross-section rather than time series data. The basic intuition is as follows. LHC only affects individuals in a certain age group (specifically 30 years of age or older), whereas the 30 per cent rebate applies across the board for all age groups. Thus, if we compare across age groups that are just below and just above the cutoff age, we can isolate the effect of LHC. This is because the effects of other two policy changes, which are common to all age groups, simply fall out when we take the difference. This 
paper concentrates only on single individuals for several reasons. First, the National Health Survey (NHS) data on families are much less complete, especially on the age of family heads and spouse, which determines the cost of PHI under LHC. The 2001 NHS does not contain information on all adults in a family unit surveyed. Secondly, the insurance decisions of singles are influenced by fewer variables, thus making the estimates more precise. Insurance decisions by a family, on the other hand, may depend on many unobserved age-related factors, such as the planned arrival of children, health states of family members. Our results suggest that the importance of LHC appears to be over-rated in previous studies. Our estimates indicate that LHC accounts for roughly 30 per cent to 44 per cent of the total effects on single individuals of all the three policy initiatives combined. This also implies that the other two policy initiatives (i.e., the tax levy and 30 per cent premium rebate) are given less credit than they should deserve. However, our results should not be construed as defending or criticising any particular policy initiative, since we have not touched on the equity and efficiency aspects of these policy initiatives.

The remainder of this paper is structured as follows. Section 2 outlines the regression discontinuity methodology. The data are discussed in Section 3, and the empirical results are presented in Section 4. Some concluding remarks are given in Section 5.

\section{Regression-Discontinuity (RD) Design}

The Regression-Discontinuity (RD) design exploits the additional information from the discontinuity of insurance decision with respect to the age variable that LHC introduces. Specifically, LHC introduces a discontinuity at age 30, and this discontinuity is particularly important during the "grace period," from September 1999 to July 2000, during which anyone above 30 years of age could avoid paying the higher premiums due to LHC by purchasing hospital insurance with a health insurance fund.

This is an example of a "sharp" RD design; see Hahn et al. (2000). In the parlance of RD design, individuals' insurance decisions are the "treatment effect," while age 
is the variable that is used for "treatment selection." Under the sharp RD design, assignment to treatment depends in a deterministic way on age, denoted $a_{i}$, with a known discontinuity at some point $\bar{a}$, where in our context $\bar{a}=30$. That is, all individuals 30 years or older are treated, whereas individuals below 30 are not treated. Let $d_{i}$ be an indicator for treatment selection, then

$$
d_{i}= \begin{cases}1 & \text { if } a_{i} \geq \bar{a} \\ 0 & \text { otherwise }\end{cases}
$$

The treatment outcome, denoted $h_{i}$, is the probability of individual $i$ purchasing PHI. We can write

$$
E\left[h_{i}\right]=\beta_{0}+\beta_{1} d_{i}
$$

where $\beta_{0} \equiv E\left[h_{i 0}\right]$ is the probability of individual purchasing PHI without the treatment, and $\beta_{1} \equiv E\left[h_{i 1}\right]-E\left[h_{i 0}\right]$ is the change in probability due to the treatment. It should be noted that under (1), the treatment effect is assumed to be common among all individuals in the sample, so that $\beta_{1}$ is the same for all individuals. If treatment effect is allowed to vary across individuals, the estimated effect can be interpreted as the local average treatment effect (Van der Klaauw, 2001).

If individuals close to $\bar{a}$ are no different from other individuals, then comparing individuals just below this threshold with individuals just above will give an unbiased estimate of the treatment effect:

$$
\beta_{1}=h^{+}-h^{-},
$$

where

$$
h^{+} \equiv \lim _{a \downarrow \bar{a}} E[h \mid a] \quad \text { and } \quad h^{-} \equiv \lim _{a \uparrow \bar{a}} E[h \mid a]
$$

Equation (2) thus forms the basis of our empirical estimation. Identification was made possible by comparing individuals arbitrarily close to the point $\bar{a}$ who did and did not receive treatment. An important identifying assumption is that there are no other discontinuities around $\bar{a}$, and that $\beta_{0}$ is continuous in $a$ around $\bar{a}$. As we shall see below, the survey data at our disposal pose some difficulties due to its very coarse age group classification, where each age group typically consists of a five year interval. We are 
doubtful that individuals in the age group just below the cutoff age, i.e., the 25-29 group, are similar to those just above the cutoff age, i.e., those in the 35-39 group. Indeed, using data from the 1995 NHS, which was conducted well before any of the policy initiatives were in place, we see that individuals in these two age groups are not quite similar in their PHI decisions. This shall become clear when we describe the data below.

\section{Data and Summary Statistics}

We implement the RD design using of data from two National Health Surveys (NHS) conducted by the Australian Bureau of Statistics (ABS): the 2001 and 1995 NHS. The NHS is a national survey of households conducted every five years to obtain information on the health status of Australians, their use of health resources, and health-related aspects of their lifestyle, in addition to the usual socio-economic and demographic characteristics. Households were selected at random using a stratified multi-stage area sample. The 2001 sample at our disposal consists of 26,862 respondent records residing in 17,918 private dwellings (houses, flats, etc.), while the 1995 sample consists of 53,828 respondent records residing in 23,800 private dwellings across Australia.

The primary source of data for this study is the 2001 NHS, which was conducted between February and November 2001. Since LHC came into effect in July 2000, we can treat the PHI information collected in this survey as the "post experiment" outcome. The basic RD design requires that we identify two groups of individuals, the "treated" and "untreated" groups, while at the same time making sure that the two groups are as similar as possible in all other aspects. Unfortunately, there are a number of data issues that make this difficult, and hence the need to make use of information from the 1995 NHS, which we exploit as a source of identifying the "pre-treatment" effect. We will return to this point below when we summarize the data using simple descriptive statistics.

Although individual respondent records in the surveys can be combined to form family 
units via an identifier in the data, we have restricted our study to single individuals only, due mainly to the lack of information on adults in families. The design of the 2001 NHS collected information on only one adult (defined as anyone 18 years of age or older) within each selected household. There is also no identifying information about whether the adult interviewed was a parent, or head of the household. In addition, the insurance decisions of families are also potentially more complex, as variables such as the planned arrival of children, health states of family members, and so on, may come into consideration. For these reasons, we choose to concentrate only on single individuals. After deleting records of individuals below 18 years (mostly students) and above 64 years (mostly retirees), and records with missing observations, we arrive at a sample of 4,718 single individuals in $2001 .^{2}$

Since LHC applies only to hospital insurance, we define private health insurance as hospital insurance cover only. Specifically, the binary variable "PHI" takes on the value of 1 if the individual has hospital insurance cover, and 0 otherwise. ${ }^{3}$ Table 1 provides a summary, by age groups, of the sample proportions and means of the variables used in the estimation. On average, 36.5 per cent of the single individuals in the sample had PHI in 2001, although the proportions vary considerably across age groups. As one would expect, income and the number of chronic conditions do correlate strongly with age.

Unfortunately, the coarse classification of age groups means that a significant amount of heterogeneity is buried within each age group. Figure 2 plots, by age groups, the actual sample proportions of single individuals with PHI. To provide a comparison, the corresponding sample proportions from the 1995 NHS are also included in the same figure. The picture shows that, beginning at age 20, the proportions of individuals with PHI rose with age, with a significant "jump" occurring around the age group 30-34,

\footnotetext{
${ }^{2}$ Another reason that those above 64 years of age are deleted from the sample is because LHC only applies to individuals below 68 years old as at July 2000. One could, in principle, apply the same RD design to those just above and below 68 years of age, but there are not enough observations to give reliable estimates.

${ }^{3}$ There are a number of individuals with ancillary but not hospital cover. These individuals are regarded as without $\mathrm{PHI}$ in the empirical estimation below.
} 
Table 1: Summary statistics by age, singles in 2001 NHS

\begin{tabular}{|c|c|c|c|c|c|c|c|}
\hline $\begin{array}{l}\text { Age } \\
\text { group }\end{array}$ & Freq. & \multicolumn{4}{|c|}{ Proportion } & $\begin{array}{c}\text { Income } \\
\text { level }\end{array}$ & $\begin{array}{l}\text { No. chronic } \\
\text { conditions }\end{array}$ \\
\hline 18-19 & 208 & 0.332 & 0.476 & 0.413 & 0.061 & 1.62 & 1.79 \\
\hline $20-24$ & 475 & 0.257 & 0.512 & 0.497 & 0.215 & 2.27 & 1.77 \\
\hline $25-29$ & 550 & 0.222 & 0.558 & 0.502 & 0.353 & 2.93 & 1.97 \\
\hline $30-34$ & 558 & 0.342 & 0.550 & 0.588 & 0.371 & 3.21 & 2.33 \\
\hline 35-39 & 600 & 0.362 & 0.545 & 0.635 & 0.299 & 3.09 & 2.42 \\
\hline $40-44$ & 587 & 0.378 & 0.555 & 0.685 & 0.332 & 3.24 & 2.52 \\
\hline $45-49$ & 524 & 0.433 & 0.590 & 0.574 & 0.337 & 3.10 & 2.97 \\
\hline $50-54$ & 467 & 0.475 & 0.507 & 0.561 & 0.368 & 3.03 & 3.44 \\
\hline $55-59$ & 383 & 0.483 & 0.572 & 0.592 & 0.290 & 2.42 & 3.64 \\
\hline 60-64 & 366 & 0.393 & 0.609 & 0.609 & 0.173 & 1.99 & 3.78 \\
\hline Overall & 4,718 & 0.365 & 0.550 & 0.577 & 0.301 & 2.812 & 2.64 \\
\hline
\end{tabular}

Notes: (a) High income refers to those in top three income deciles.

(b) Income level refers to annualised gross income in $\$ 10,000$.

Figure 2: Sample proportion of single individuals with PHI, 2001 and 1995

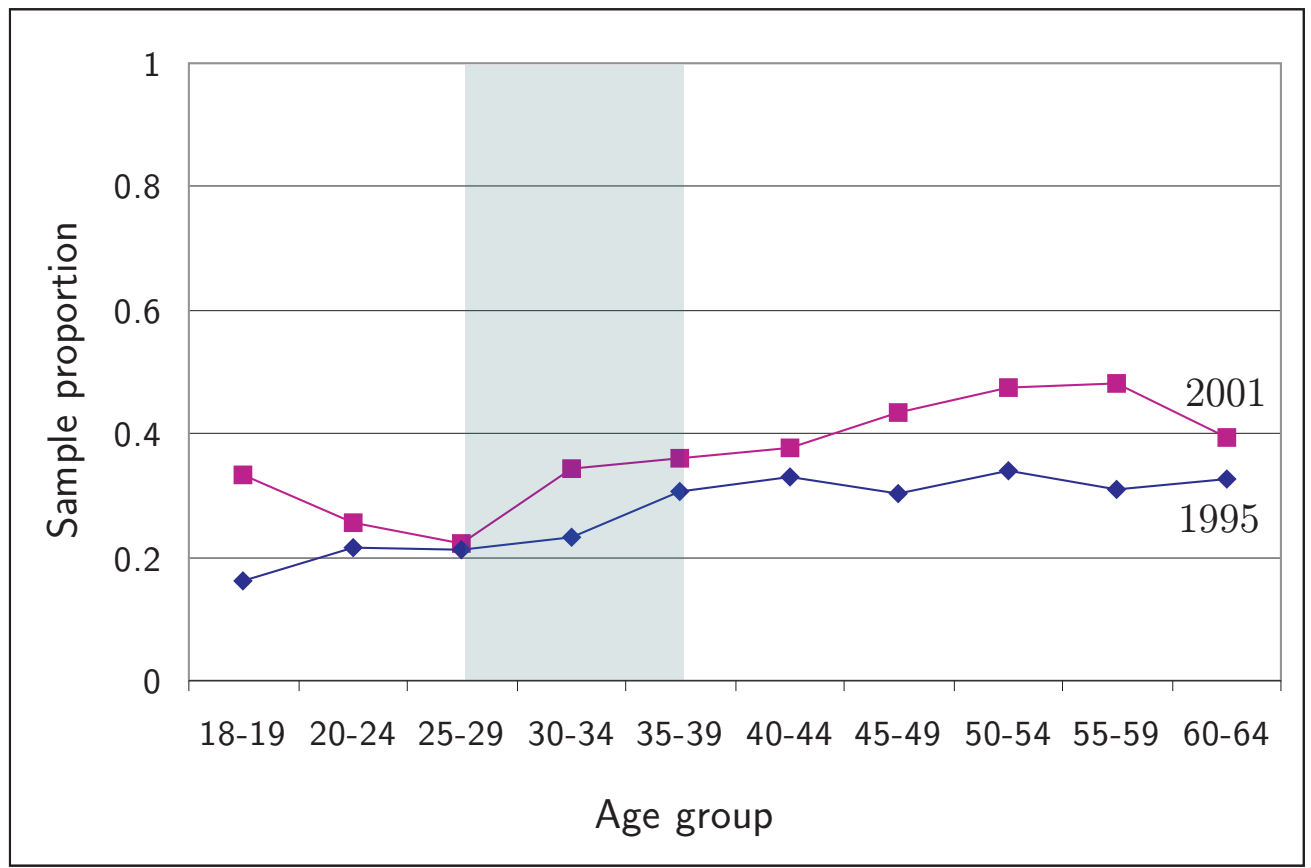


although the jump appears to be particularly pronounced for 2001. We think there are two possible explanations for this observation. First, income is highly correlated with age, hence the jump could quite possibly reflect the fact that there are more older individuals in higher income brackets. Indeed, the proportions of high-income individuals in the sample as reported in Table 1 do increase with age, at least initially.

Figure 3 therefore separates the plots according to income groups. Two separate plots are presented, one for low-income and the other for high-income groups, of the proportions of individuals with PHI by age groups. We use income deciles to form the income groups. By low income, we refer to those individuals whose incomes are in the bottom three deciles. The high-income group consists of individuals whose incomes are in the top three deciles. Figure 3 depicts a very different picture for the two income groups. For the low-income group, there is no discernible jump in the proportion of individuals with PHI as age rises, whereas the jump becomes even more pronounced for the high-income group, and more so for 2001 than 1995. The fact that the proportions of low-income individuals with PHI hardly changed between the two surveys shows that all the policy initiatives introduced during the intervening period have had no effect on these individuals.

Figure 3 also shows that the jump in the proportion with PHI across age for those in the 25-29 and 34-39 age groups remains and is even more pronounced for highincome individuals. This brings to our second explanation that there could be other, unobserved but age-correlated, demographic factors that were influencing individuals' insurance decisions. This conjecture can be verified by examining a finer age group classification, but this is not possible with the particular version of confidentialised NHS data we have. Comparing 2001 and 1995, we see that the introduction of LHC, coupled with other policy changes, not only raised the proportions of individuals with PHI, but also appears to have brought forward the decisions of individuals to purchase PHI, i.e., at a younger age, and this is especially obvious for high-income individuals. 
Figure 3: Sample proportion of single individuals with PHI by income, 2001 and 1995

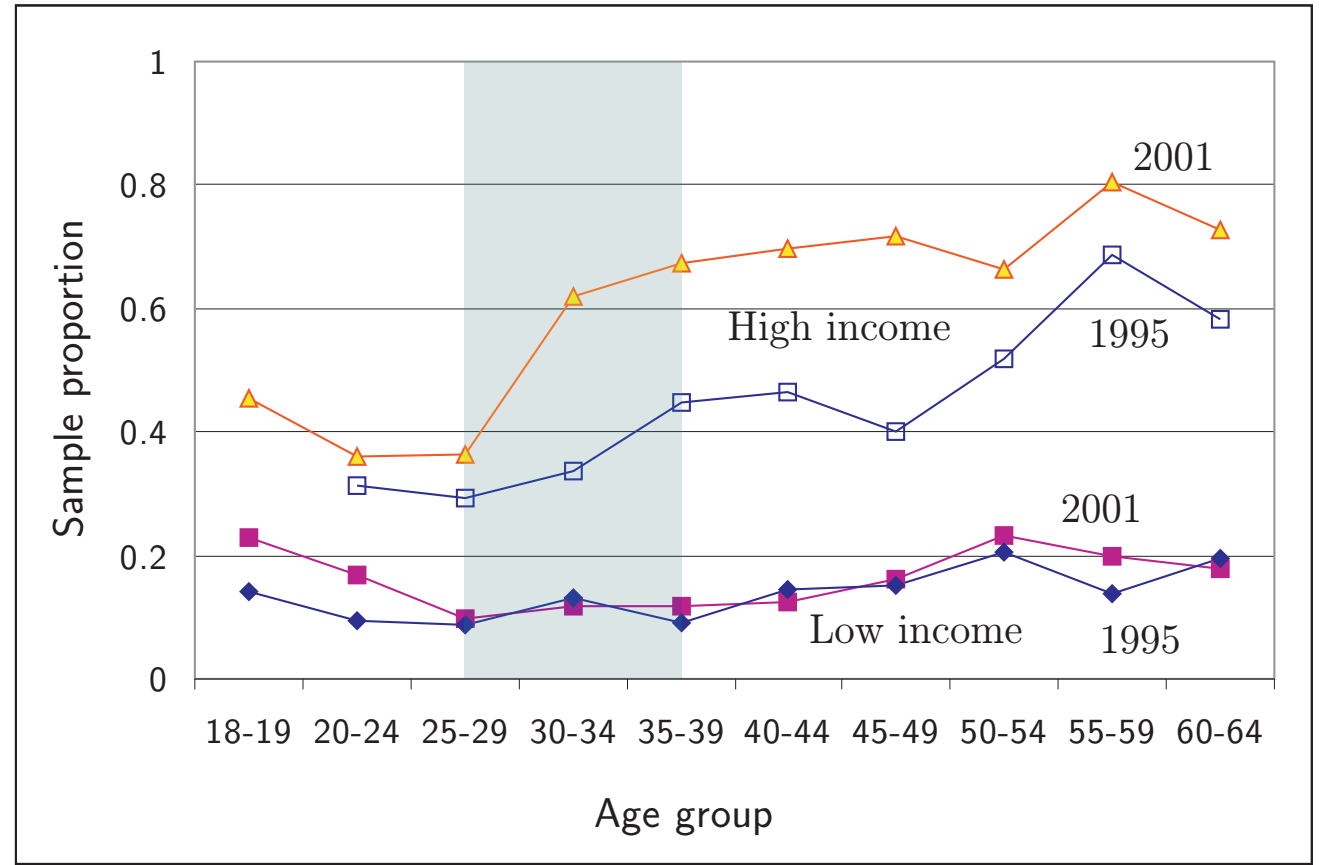

\section{Empirical Results}

The possible existence of unobserved but age-correlated factors pose a particular problem for the application of the $\mathrm{RD}$ approach. Recall that the $\mathrm{RD}$ design requires the comparison of two groups of individuals that are as similar as possible in all aspects except the treatment they receive. Here, the "treatment" is the penalty of paying higher premiums under LHC, and the selection is by age: those who are above 30 years of age are subject to higher premiums, while those who are younger than 30 years are not. Ideally we would like to have a sample of individuals who are just above and below the cutoff age in year 2000. This means, for the 2001 NHS, individuals who are, respectively, 30 and 32 years of age. However, the age classification is too coarse, the closest two age groups turn out to be dissimilar, as depicted in Figures 2 and 3. Hence, the estimated treatment effect, obtained by comparing these two groups of individuals, must be adjusted for the unobserved age-correlated factors. For this, we rely on the 1995 NHS data to obtain a form of "difference-in-difference" estimates. To proceed, we estimate 
the proportions of individuals with PHI just below (i.e., 25-29) and those just above (i.e., 35-39) the cutoff age from the 2001 NHS data. The former serves as the control group, which are not affected by LHC, whereas the latter is the treatment group, which are affected by LHC. Both groups are affected by all other policy changes, including the 30 per cent rebates, tax levy, and advertising campaign. The difference between these two age groups provides an estimate of the combined effects of LHC and the unobserved age-correlated factors. The latter's effect is isolated by comparing estimates for the same two age groups from the 1995 NHS data, which clearly does not contain the effect of LHC. In this sense, the difference (across the two surveys) in difference (between the two age groups) provides an estimate the effect of LHC. The issue that remains is to find consistent estimates of the effects using data from the two surveys.

Figure 4 presents the predicted proportion of single individuals with PHI using local linear regression (Cleveland, 1979; Cleveland et al., 1988). ${ }^{4}$ The same computation is performed for both the 2001 and 1995 NHS data. It is worth noting that the predicted proportions were almost identical for the 25-29 age group in both surveys, while for the older age groups the divergence between the two surveys become more pronounced. At the same time, there is also a pronounced increase in PHI coverage as we go from the 25-29 to 35-39 age groups. This is true for both surveys, although more so for the 2001 sample.

While the local linear regression gives consistent estimates, it does not allow for the use of additional control variables in the estimation. We use instead OLS to estimate the jump by restricting the regression to the two age groups closest to the cutoff age. Conceptually, this is the same as performing a local regression, although a different weighting scheme is used.

Table 2 provides a summary of the various estimates of the effect of LHC using the $\mathrm{RD}$ design outlined above. To estimate the jump, we use data of the two closest age groups to the cutoff age, which is age 30 as at 15 July 2000. We omit the age group 30-34, as it contains individuals who were above as well as below the cutoff age when

\footnotetext{
${ }^{4}$ The computation is performed in STATA using the command LOWESS, with the default bandwidth of 0.8 .
} 
Figure 4: Predicted proportion of single individuals with PHI, 2001 and 1995

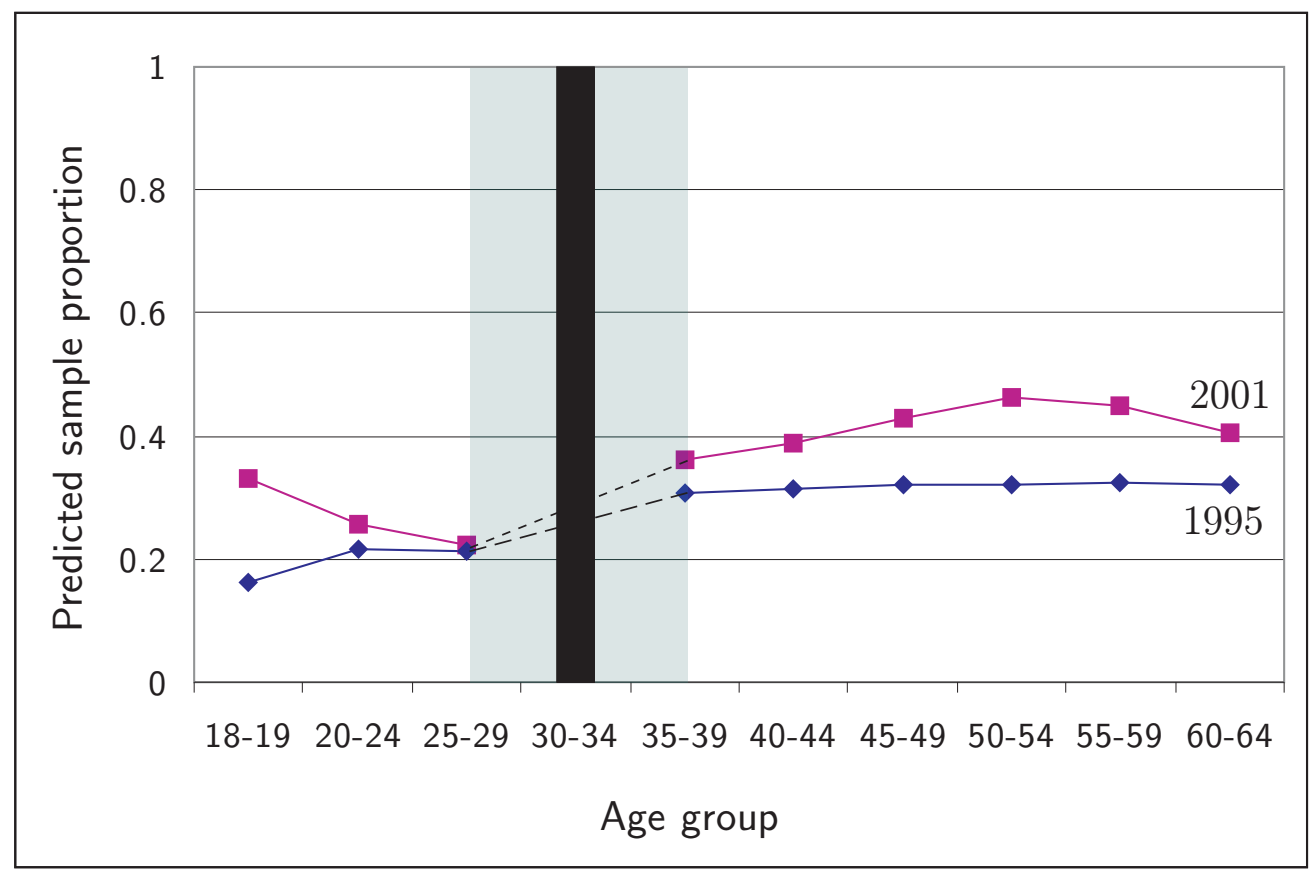

LHC was introduced. The two closest age groups are 25-29 and 35-39, and there are 1,150 individuals in these two age groups in total. We define a age dummy variable (1 being those in the 35-39 age group), and execute a linear probability model (Heckman and Snyder, 1997) by regressing individuals' PHI status on the age dummy using OLS. To check for robustness, we also introduce control variables in some cases. The control variables we use include sex, individuals' income, number of chronic conditions, whether current or ex-regular smoker, and self-assessed health. The same exercise is repeated using data from the 1995 NHS, thus allowing the effect of the unobserved age-correlated factors to be isolated. The difference-in-difference estimate is obtained by subtracting the latter estimate from the former. The standard error of the difference-in-difference estimate, denoted $s_{d}$, is obtained according to the standard formula of a pooled variance estimate:

$$
s_{d}=\sqrt{\frac{\left(n_{2001}-1\right) s_{2001}^{2}+\left(n_{1995}-1\right) s_{1995}^{2}}{n_{2001}+n_{1995}-2}},
$$

where $n_{2001}$ and $s_{2001}$ denote respectively the sample size and estimated standard error from the 2001 NHS; while $n_{1995}$ and $s_{1995}$ are analogously defined.

The estimated effect of LHC for the overall sample are very significant, both statistically 
Table 2: Estimated effects of LHC

\begin{tabular}{|c|c|c|c|c|c|}
\hline \multirow{4}{*}{ Dep. variable: $\mathrm{PHI}$} & \multirow{2}{*}{\multicolumn{2}{|c|}{$2001 \mathrm{NHS}$}} & \multirow{2}{*}{\multicolumn{2}{|c|}{$1995 \mathrm{NHS}$}} & \multirow{4}{*}{$\begin{array}{c}\text { Difference } \\
\text { LHC } \\
\text { effect }\end{array}$} \\
\hline & & & & & \\
\hline & Total & Sample & Age & Sample & \\
\hline & effect & size & effect & size & \\
\hline \multirow[t]{2}{*}{ Overall } & $0.140^{* *}$ & 1,150 & $0.093^{* *}$ & 1,027 & $0.047^{\dagger}$ \\
\hline & $(0.0266)$ & & $(0.0288)$ & & $(0.0277)$ \\
\hline \multirow[t]{2}{*}{ Overall with controls } & $0.153^{* *}$ & 1,150 & $0.085^{* *}$ & 915 & $0.068^{*}$ \\
\hline & $(0.0254)$ & & $(0.0290)$ & & $(0.0271)$ \\
\hline \multirow[t]{2}{*}{ Low income } & 0.020 & 387 & 0.002 & 216 & 0.017 \\
\hline & $(0.0319)$ & & $(0.0419)$ & & $(0.0358)$ \\
\hline \multirow[t]{2}{*}{ Medium income } & $0.147^{* *}$ & 349 & $0.090^{\dagger}$ & 358 & 0.056 \\
\hline & $(0.0468)$ & & $(0.0489)$ & & $(0.0480)$ \\
\hline \multirow[t]{2}{*}{ High income } & $0.309^{* *}$ & 355 & $0.154^{* *}$ & 368 & $0.155^{* *}$ \\
\hline & $(0.0507)$ & & $(0.0517)$ & & $(0.0513)$ \\
\hline \multirow[t]{2}{*}{ Low income with controls } & 0.035 & 387 & 0.001 & 216 & 0.033 \\
\hline & $(0.0314)$ & & $(0.0422)$ & & $(0.0357)$ \\
\hline \multirow[t]{2}{*}{ Middle income with controls } & $0.162^{* *}$ & 349 & 0.071 & 358 & $0.091^{\dagger}$ \\
\hline & $(0.0470)$ & & $(0.0477)$ & & $(0.0474)$ \\
\hline \multirow[t]{2}{*}{ High income with controls } & $0.331^{* *}$ & 355 & $0.160^{* *}$ & 368 & $0.172^{* *}$ \\
\hline & $(0.0515)$ & & $(0.0521)$ & & $(0.0519)$ \\
\hline
\end{tabular}

Figures in parentheses are estimated standard errors.

Significance levels : $\quad \dagger: 10 \% \quad *: 5 \% \quad * *: 1 \%$ 
and economically. LHC is estimated to raise the percentage of singles with PHI by 4.7 percentage points if no control variables are introduced, and the effect increases to 6.8 percentage points with control variables. Table 3 shows the parameter estimates when control variables are introduced; the left half of the table shows the estimates using 2001 NHS data, while the right half show results from the 1995 NHS data.

It is important to note that the effect of LHC vary considerably between income groups. This can be seen clearly when the sample is divided into three subsamples according to individuals' income deciles. For the low-income individuals, the effect is not significantly different from zero, and this is the case whether we add control variables in the regression or not. On the other hand, the effect on the high income group is much higher than average, at respectively 15.5 and 17.2 percentage points, depending on whether control variables are introduced. The estimated effect is also highly statistically significant in both cases. The effect on the middle income group appears to be somewhat in between the two extremes, at 5.6 and 9.1 percentage points, depending on whether control variables are used. OLS estimates for the three income groups subsamples when control variables are introduced can be found in Appendix A.

To put the estimated effect of LHC into context, we note that results from an earlier study by Palangkaraya and Yong (2004) show the combined effects of all PHI policy initiatives introduced in the late 1990s raised PHI coverage of single individuals by 15.5 percentage points. ${ }^{5}$ Thus, the estimated effect of LHC we obtained accounts for roughly 30 to 44 per cent of the combined effects of all policy changes, depending on whether the control variables are used. We emphasize, however, that the estimates are found to vary considerably across income groups. Unfortunately, we are not able to estimate the proportion of the combined effects that LHC accounts for by income groups, as the earlier study did not attempt to separately estimate the effects by income groups.

\footnotetext{
${ }^{5}$ An alternative, albeit somewhat dubious, estimate is to take the difference between the sample proportion of single individuals with PHI in 2001 and 1995. In our case, the overall sample proportion of individuals with PHI is 0.365 for 2001 and 0.25 for 1995, the difference of 0.115 is thus a rough estimate of the total combined effects. This is, however, likely to underestimate the combined effects, since PHI membership is, from Figure 1, clearly on a declining trend. This means the proportion of individuals with PHI would have been even lower by 2001 had there been no policy initiatives.
} 
Table 3: OLS estimates of overall sample with controls, dependent variable: PHI

\begin{tabular}{|c|c|c|c|c|c|c|}
\hline \multirow[b]{2}{*}{ Dep. Variable: PHI } & \multicolumn{3}{|c|}{2001 NHS sample } & \multicolumn{3}{|c|}{1995 NHS sample } \\
\hline & $\begin{array}{l}\text { Parameter } \\
\text { estimate }\end{array}$ & $\begin{array}{l}\text { Std. } \\
\text { error }\end{array}$ & t-value & $\begin{array}{l}\text { Parameter } \\
\text { estimate }\end{array}$ & $\begin{array}{l}\text { Std. } \\
\text { error }\end{array}$ & t-value \\
\hline Age dummy: $1=35-39$ yrs & 0.152 & 0.0254 & 6.01 & 0.085 & 0.0291 & 2.91 \\
\hline Sex: $1=$ female & 0.031 & 0.0254 & 1.22 & 0.051 & 0.0272 & 1.87 \\
\hline Income & 0.060 & 0.0061 & 9.68 & 0.071 & 0.0087 & 8.19 \\
\hline No. chronic cond. $(0-5)$ & 0.017 & 0.0080 & 2.17 & 0.013 & 0.0077 & 1.74 \\
\hline Dummy: $1=$ fair health & -0.137 & 0.0375 & -3.65 & -0.112 & 0.0447 & -2.50 \\
\hline Dummy: $1=$ smoker & -0.134 & 0.0258 & -5.20 & -0.106 & 0.0284 & -3.73 \\
\hline Constant & 0.077 & 0.0358 & 2.16 & 0.022 & 0.0356 & 0.63 \\
\hline Degree of freedom & \multicolumn{3}{|c|}{1,143} & \multicolumn{3}{|c|}{915} \\
\hline Adj. $R^{2}$ & \multicolumn{3}{|c|}{0.149} & \multicolumn{3}{|c|}{0.115} \\
\hline
\end{tabular}

\section{Conclusion}

This paper applies the regression discontinuity approach to cross-section health survey data to estimate the effect of Lifetime Health Cover, one of the three major policy initiatives introduced by the Australian government in the late 1990s. The policy initiatives were aimed at reversing the declining trend in private health insurance coverage. Lifetime Health Cover is widely regarded as the most effective of all policy initiatives, yet is the cheapest in terms of the government's fiscal burden. Making use of data from the 2001 and 1995 National Health Surveys on single individuals, we show that Lifetime Health Cover did have an important and significant effect on health insurance choices. We estimate that Lifetime Health Cover alone may be responsible for 4.7 to 6.8 percentage points rise in the PHI coverage for single individuals. This represents roughly 30 to 44 per cent of the total combined effects of all policy changes introduced during the late 1990s. While the estimated effects are large, they are nowhere near the magnitude commonly attributed to Lifetime Health Cover. Our results therefore suggest that the 
importance of LHC is over-rated, and by extension, the importance of the 30 per cent premium rebate and tax levy is under-rated in earlier studies. 


\section{References}

[1] Butler, J.R.G. (2002), "Policy Change and Private Health Insurance: Did the Cheapest Policy Do the Trick?" Australian Health Review, 25(6), 33-41.

[2] Cleveland, W.S. (1979), "Robust Locally Weighted Regression and Smoothing Scatterplots," Journal of the American Statistical Association, 74, 829-36.

[3] Cleveland, W., S.J. Devlin, and E. Grosse (1988), "Regression by local fitting," Journal of Econometrics, 37, 87-114.

[4] Cormack, M. (2002), "Private Health Insurance: The Problem Child Faces Adulthood," Australian Health Review, 25(2), 38-51.

[5] Frech, H.E. III, S. Hopkins, and G. MacDonald (2003), "The Australian Private Health Insurance Boom: Was it Subsidies or Liberalised Regulation?" Economic Papers, 22(1), 58-64.

[6] Hahn, J., P. Todd, and W. Van der Klaauw (2001), "Identification and Estimation of Treatment Effects with a Regression-Discontinuity Design," Econometrica, 69(1), $201-9$.

[7] Heckman, J.J. and J.M. Snyder (1997), "Linear Probability Models of the Demand for Attributes with an Empirical Application to Estimating the Preferences of Legislators," Rand Journal of Economics, 28, S142-89.

[8] Hancock, J. and P. Neal (2003), Review of Lifetime Health Cover Scheme, Department of Health and Ageing, Canberra: Commonwealth of Australia.

[9] Leuven, E. and H. Oosterbeek (2000), "Evaluating the Effect of Tax Deductions on Training," Working Paper, Department of Economics, Universiteit van Amsterdam.

[10] Palangkaraya, A. and J. Yong (2004), "Discerning the Effects of Recent Private Health Insurance Policy Changes in Australia," Working Paper, Melbourne Institute of Applied Economic and Social Research, University of Melbourne.

[11] Quinn, C. (2002), "The Pasts and Futures of Private Health Insurance in Australia," Working Paper, no. 47, National Centre for Epidemiology and Population Health, The Australian National University, Canberra.

[12] Scotton, R.B and C.R. McDonald (1993), "The Making of Medibank," Australian Studies in Health Service Administration, No. 76, Sydney: The University of New South Wales.

[13] Van der Klaauw, W. (2001), "Estimating the Effect of Financial Aid Offers on College Enrollment: A Regression-Discontinuity Approach," International Economic Review, forthcoming. 


\section{Appendix A}

This appendix consists of results from the linear probability models with control variables. These are OLS estimates from regressing PHI (a binary variable) on the control variables, which include sex, number of chronic conditions, self-assessed health state, and smoking habit. The same regressions are run on data from the 2001 and 1995 NHS. Table 4 presents results from the 2001 NHS, whereas Table 5 contains results using data from the 1995 NHS. 
Table 4: OLS estimates by income groups and with controls, 2001 NHS

\begin{tabular}{|c|c|c|c|}
\hline Dep. variable: $\mathrm{PHI}$ & $\begin{array}{l}\text { Parameter } \\
\text { estimate }\end{array}$ & $\begin{array}{c}\text { Standard } \\
\text { error }\end{array}$ & t-value \\
\hline \multicolumn{4}{|l|}{ Low income } \\
\hline Age dummy: $1=35-39$ age group & 0.035 & 0.0314 & 1.10 \\
\hline Sex: $1=$ female & -0.007 & 0.0332 & -0.22 \\
\hline No. chronic conditions (0-5) & 0.013 & 0.0095 & 1.33 \\
\hline Dummy: $1=$ less than fair health & -0.080 & 0.0386 & -2.07 \\
\hline Dummy: $1=$ smoker & -0.156 & 0.0340 & -4.57 \\
\hline Constant & 0.194 & 0.0431 & 4.51 \\
\hline Degree of freedom & & 381 & \\
\hline Adj. $R^{2}$ & & 0.053 & \\
\hline \multicolumn{4}{|l|}{ Middle income } \\
\hline Age dummy: $1=35-39$ age group & 0.162 & 0.0470 & 3.44 \\
\hline Sex: $1=$ female & 0.086 & 0.0475 & 1.82 \\
\hline No. chronic conditions (0-5) & 0.007 & 0.0158 & 0.47 \\
\hline Dummy: $1=$ less than fair health & -0.152 & 0.0808 & -1.87 \\
\hline Dummy: $1=$ smoker & -0.114 & 0.0481 & -2.37 \\
\hline Constant & 0.197 & 0.0529 & 3.73 \\
\hline Degree of freedom & & 343 & \\
\hline Adj. $R^{2}$ & & 0.055 & \\
\hline \multicolumn{4}{|l|}{ High income } \\
\hline Age dummy: $1=35-39$ age group & 0.331 & 0.0515 & 6.43 \\
\hline Sex: $1=$ female & 0.194 & 0.0527 & 3.69 \\
\hline No. chronic conditions (0-5) & 0.029 & 0.0165 & 1.76 \\
\hline Dummy: $1=$ less than fair health & -0.112 & 0.0956 & -1.17 \\
\hline Dummy: $1=$ smoker & -0.030 & 0.0505 & -0.59 \\
\hline Constant & 0.236 & 0.0518 & 4.55 \\
\hline Degree of freedom & & 349 & \\
\hline Adj. $R^{2}$ & & 0.139 & \\
\hline
\end{tabular}


Table 5: OLS estimates by income groups and with controls, 1995 NHS

\begin{tabular}{|c|c|c|c|}
\hline Dep. variable: $\mathrm{PHI}$ & $\begin{array}{c}\text { Parameter } \\
\text { estimate }\end{array}$ & $\begin{array}{c}\text { Standard } \\
\text { error }\end{array}$ & t-value \\
\hline \multicolumn{4}{|l|}{ Low income } \\
\hline Age dummy: $1=35-39$ age group & 0.0015 & 0.0422 & 0.03 \\
\hline Sex: $1=$ female & -0.0508 & 0.0413 & -1.23 \\
\hline No. chronic conditions $(0-5)$ & 0.0003 & 0.0096 & 0.03 \\
\hline Dummy: $1=$ less than fair health & -0.0333 & 0.0587 & -0.57 \\
\hline Dummy: $1=$ smoker & -0.1011 & 0.0393 & -2.58 \\
\hline Constant & 0.1534 & 0.0355 & 4.32 \\
\hline Degree of freedom & & 216 & \\
\hline Adj. $R^{2}$ & & 0.019 & \\
\hline \multicolumn{4}{|l|}{ Middle income } \\
\hline Age dummy: $1=35-39$ age group & 0.0710 & 0.0477 & 1.49 \\
\hline Sex: $1=$ female & 0.0643 & 0.0428 & 1.50 \\
\hline No. chronic conditions $(0-5)$ & 0.0312 & 0.0130 & 2.39 \\
\hline Dummy: $1=$ less than fair health & -0.1636 & 0.0879 & -1.86 \\
\hline Dummy: $1=$ smoker & -0.1618 & 0.0447 & -3.62 \\
\hline Constant & 0.1830 & 0.0396 & 4.62 \\
\hline Degree of freedom & & 358 & \\
\hline Adj. $R^{2}$ & & 0.066 & \\
\hline \multicolumn{4}{|l|}{ High income } \\
\hline Age dummy: $1=35-39$ age group & 0.1597 & .0521 & 3.06 \\
\hline Sex: $1=$ female & 0.0466 & .0505 & 0.92 \\
\hline No. chronic conditions $(0-5)$ & 0.0026 & .0145 & 0.18 \\
\hline Dummy: $1=$ less than fair health & -0.1454 & .0923 & -1.58 \\
\hline Dummy: $1=$ smoker & -0.0951 & .0539 & -1.76 \\
\hline Constant & 0.3093 & .0468 & 6.61 \\
\hline Degree of freedom & & 368 & \\
\hline Adj. $R^{2}$ & & 0.031 & \\
\hline
\end{tabular}

